\title{
Environmentally controlled phenotypic plasticity of morphology and polypeptide expression in two populations of Daphnia pulex (Crustacea: cladocera)
}

\author{
Lester W. Lee \\ Division of Biological Sciences, Natural Science Building and Museum of Zoology, University of Michigan, \\ Ann Arbor, MI 48109-1048, USA
}

\begin{abstract}
Summary. Two local Daphnia pulex populations which are subject to different types of seasonally varying predation pressures were studied. Individuals from both populations were raised in laboratory environments which simulated either summer or winter temperatures and photoperiods. When individuals from the same parthenogenetic clone were raised in different seasonal environments, each clone exhibited phenotypic variation specific to each of the seasonal environments. Intraclonal phenotypic plasticity was found in both populations at two different levels: variation in morphological characters, and variation in the expressed polypeptide phenotypes. Summer environmental conditions induced predator-resistant morphological traits, while winter conditions induced predator-susceptible ones. From $65 \%$ to $71 \%$ of over 200 major polypeptides were specifically expressed in either one seasonal environment or the other. This is evidence for the existence of environmentally induced switching between alternate developmental programs. Clones from the population with the least year to year predictability of seasonal predation pressure showed more interclonal variation in environment specific phenotypic expression than clones from the more predictably fluctuating environment.
\end{abstract}

Among many cladoceran populations it is common to observe seasonally cyclic variation in certain morphological characters. Such seasonal phenotypic changes have also been observed among many species of planktonic algae, rotifers, and crustaceans, and the term, "cyclomorphosis", was coined by Lauterborn (1904) to describe this phenomenon. For cladocerans these variable characters include intraspecific dimorphisms in head shape, carapace size, eye size, tail spine length, and antennule length (reviewed by Hutchinson 1967; Kerfoot 1980).

There is considerable evidence that certain of these variable morphological characters reduce an individual's susceptibility to predation (Brooks 1968; Dodson 1974; Fedorenko 1975; Galbraith 1967; Kerfoot 1978; O'Brien et al. 1979). Because of the apparent selective advantages of the predator-resistant morphological traits in reducing mortality by predation, these phenotypes might be expected to become fixed in cladoceran populations. However, the population densities of the predator species, and hence, predation pressures, fluctuate seasonally, and individuals possess- ing predator-resistant phenotypes tend to be at a competitive disadvantage relative to the predator-susceptible phenotypes in the absence of predation (Jacobs 1966; Kerfoot 1977 b; O'Brien and Vinyard 1978; Zaret 1972). Predation pressures tend to be highest during the spring and summer, and at their lowest during the winter. Thus, there is a seasonal cycle of change in the selective coefficients for each of the above sets of phenotypes.

Given that Daphnia commonly occur in such predictably fluctuating seasonal environments, that they are relatively short-lived, with generation times on the order of days or weeks, and that they reproduce predominately by apomictic parthenogenesis (Hebert and Ward 1972; Zaffagnini and Sabelli 1972), Kerfoot (1980) has argued that cyclomorphosis is a complex adaptation, resulting from selection favoring genotypes which were capable of asexually producing a succession of generations with different, adaptive phenotypes in response to specific environmental cues which signal predictable seasonal change.

If this argument is correct, two predictions can be made about populations inhabiting predictable environments. Firstly, cyclomorphosis should be controlled by alternate developmental programs which are switched on or off by specific environmental cues. Secondly, there should be more genetic polymorphism at the loci controlling the expression of these phenotypically plastic traits in populations inhabiting less predictable environments. The present study was undertaken to characterize and quantify the phenotypic variation observed in two different populations of Daphnia pulex which are subjected to different degrees of year to year predictability of seasonally changing predation pressures in order to test these two predictions.

\section{Materials and methods}

Daphnia pulex populations. Two different populations of D. pulex from southeastern Michigan were studied: i) Third Sister Lake, situated about $4 \mathrm{~km}$ west of Ann Arbor in the Saginaw Forest, is owned by the University of Michigan and maintained with restricted public access. This lake has a surface area of $38,500 \mathrm{~m}^{2}$ and a maximum depth of $16.5 \mathrm{~m}$. ii) The second population occurs in Rash Pond, which is located at the University of Michigan Matthaei Botanical Gardens. Rash Pond is a small, shallow, abandoned gravel pit which has become a permanent body of water approximately $1,000 \mathrm{~m}^{2}$ in area and $2 \mathrm{~m}$ in depth. 
Collection and laboratory cultivation. Zooplankton were sampled from both Third Sister Lake and Rash Pond at irregular intervals in all seasons between June 1976 and July 1979. Samples from Third Sister Lake were collected either as vertical hauls from $10 \mathrm{~m}$ depth to the surface using a $1.0 \mathrm{~m}$ diameter, conical plankton net, or a 391 SchindlerPatalas Trap. Samples from Rash Pond were taken with a $20 \mathrm{~cm}$ diameter, conical plankton net. Parthenogenetic clones were established from individual progeny of adult females collected from the field. The culture medium for the Daphnia consisted of Ann Arbor tap water which had been "aged" in plastic drums by addition of $5 \mathrm{ml} 0.6 \mathrm{M}$ sodium thiosulfate to 1501 of tap water and constant aeration for at least 10 days at $20^{\circ}$. Food was provided as suspensions of Ankistrodesmus (a non-clumping strain from the University of California, Berkeley Micro-Botanical Collection) in a concentration of $5 \times 10^{3}$ cells per $\mathrm{ml}$. The algae were pure cultured in Modified Hoagland's Solution: $1.18 \mathrm{~g}$ $\mathrm{Ca}\left(\mathrm{NO}_{3}\right)_{2} \cdot 4 \mathrm{H}_{2} \mathrm{O}, \quad 593 \mathrm{mg} \quad \mathrm{MgSO}_{4} \cdot 7 \mathrm{H}_{2} \mathrm{O}, \quad 150 \mathrm{mg}$ $\mathrm{KH}_{2} \mathrm{PO}_{4}, 564 \mathrm{mg} \mathrm{KNO}, 24.9 \mathrm{mg} \mathrm{FeSO} \cdot 7 \mathrm{H}_{2} \mathrm{O}, 33.3 \mathrm{mg}$ $\mathrm{Na}_{2}$ EDTA, $2.90 \mathrm{mg} \quad \mathrm{H}_{3} \mathrm{BO}_{3}, 1.83 \mathrm{mg} \quad \mathrm{MnCl}_{2} \cdot 4 \mathrm{H}_{2} \mathrm{O}$, $0.08 \mathrm{mg} \mathrm{CuSO}, 0.02 \mathrm{mg}\left(\mathrm{NH}_{4}\right)_{6} \mathrm{Mo}_{7} \mathrm{O}_{24} \cdot 4 \mathrm{H}_{2} \mathrm{O}, 0.41 \mathrm{mg}$ $\mathrm{ZnSO}_{4} \cdot 7 \mathrm{H}_{2} \mathrm{O}, 4.0 \mathrm{~g}$ Glucose, and $250 \mathrm{mg}$ Proteose peptone (DIFCO) per 1 .

Experiments were conducted by placing groups of ten adult individuals from the same clone into $75 \mathrm{ml}$ culture vessels. Replicate groups were placed in both of two incubators set at the following temperatures and photoperiods: $22^{\circ}, 16 \mathrm{~h}$ of light to $8 \mathrm{~h}$ of darkness for the summer conditions, and $6^{\circ}, 8 \mathrm{~h}$ of light to $16 \mathrm{~h}$ of darkness for the winter conditions. These conditions approximate the most extreme seasonal values experienced by these populations in the field. The cultures were grown for a minimum of two weeks to allow physiological acclimation. Medium was changed weekly and population density in these cultures was held constant by daily removal of neonates. These culture conditions allowed the indefinite propagation of isogenic lines of parthenogenetically reproducing females.

Morphological measurements. A Quantimet 720 Image Analysis Facility was used to make morphological measurements on females in their second or third adult instar within $24 \mathrm{~h}$ of being fixed in a $4 \%$ buffered formalin, $5.75 \%$ sucrose solution. The following measurements were taken: carapace length, maximum carapace width, tail spine length, lateral areas of the whole carapace, compound eye, gut tube and ovaries, and the thoracic appendages. The lateral area of the non-transparent internal organs and compound eye (i.e. those features most conspicuous to a visual predator) was determined by measuring the "detected area" within the carapace. The detected area refers to the area of all features within the outline of the carapace which are more opaque than the carapace, itself. Mean optical densities of the compound eye, gut and ovaries, thoracic appendages, and the carapace were measured. Individuals from a single clone of Daphnia pulex from Third Sister Lake were compared to individuals from a single clone from Rash Pond.

Results were statistically analyzed using a two-tailed Mann-Whitney $\mathbf{U}$ test to make pairwise comparisons within localities, between environments, and within environments, between localities. Simple ratios of length measurements to carapace length and of area measurements to carapace area were used as shape variables (Mosimann and James
1979). The Bonferroni Inequalities (Feller 1968) approach was used to compensate for the lack of independence resulting from each data set being used in two comparisons. Therefore, the probabilities derived from the $U$ test must be less than 0.025 to be significant at an overall experimentwise $\alpha=0.05$.

Preparation of protein samples. Each sample consisted of one female early in the second or third adult instar, prior to egg deposition into the brood pouch. Each individual was placed in about $400 \mathrm{ml}$ of aerated tap water containing $100 \mathrm{mg} / 1$ streptomycin $\mathrm{SO}_{4}$ to kill any possible symbiotic bacteria living in the gut, and a mock meal of suspended kaolin particles to purge the gut of food material and bacteria. The animal was left under these conditions for about two hrs, washed thoroughly in distilled water, and homogenized in a glass tissue homogenizer, in $200 \mu \mathrm{l}$ of the following buffer solution: $0.025 \mathrm{M}$ sodium phosphate buffer at $\mathrm{pH} 7.4,1 \mathrm{mM}$ phenylmethylsulfonylfluoride (a protease inhibitor). The homogenate was subjected to three cycles of freezing (in a dry ice-ethanol bath) and thawing, and then added to appropriate amounts of $\mathrm{MgCl}_{2}$, pancreatic ribonuclease and $\mathrm{PO}_{4}$ buffer at $\mathrm{pH} 7.4$ for a final concentration of $5 \mathrm{mM} \mathrm{Mg}^{++}, 50 \mu \mathrm{g}$ of ribonuclease per $\mathrm{ml}$, and $0.125 \mathrm{M}$ $\mathrm{PO}_{4}$ buffer. Dissolved protein was recovered from the supernatant after centrifugation.

Radioisotopic labelling of proteins. Daphnia proteins were labelled in vitro by radioiodination of tyrosine residues, i) to label nearly all of the expressed proteins present in an individual at a given time, rather than the subset of de novo synthesized proteins which would be labelled during an in vivo labelling experiment; and ii) to label the very small amounts of protein from a single Daphnia pulex with a sufficiently high specific radioactivity for detection by autofluorographic techniques. The catalyst used in all iodination reactions was $1,3,4,6$-tetrachloro-3 $\alpha, 6 \alpha$-diphenylglycoluril (Pierce Chemical Co.), as described by Fraker and Speck (1978). A $50 \mu \mathrm{l}$ aliquot of a $1.0 \mathrm{mg} / \mathrm{ml}$ solution of the catalyst in methylene chloride was placed into the reaction vessel (a $75 \mathrm{~mm} \times 10 \mathrm{~mm}$ glass culture tube) and plated onto its walls by allowing the solvent to evaporate. The catalyst is insoluble in water and active in solid state. The iodination reaction was carried out for $15 \mathrm{~min}$ at room temperature by adding to the catalyst-coated reaction vessel: $200 \mu \mathrm{l}$ of protein sample solution, 50 to $60 \mu \mathrm{Ci}$ of ${ }^{1.25} \mathrm{I}$ as $\mathrm{NaI}$, and $10 \mu \mathrm{l}$ of a $0.003 \%$ solution of unlabelled KI. Final urea concentration was then adjusted to $8 \mathrm{M}$. The labelled protein was then separated from unreacted ${ }^{125} \mathrm{I}$ by gel filtration through Bio-Gel P-2, 100-200 mesh (Bio-Rad Laboratories), using a modification of the technique described by McGhee and von Hippel (1977). Bio-Gel beads were hydrated in $8 \mathrm{M}$ urea and then packed into Pasteur pipettes, to a gel column length of about $70 \mathrm{~mm}$. The void volume was gently centrifuged out of the pipette, the iodinated protein sample loaded onto the top of the column, and then recentrifuged. The filtrate was then added to an equal volume of O'Farrell's (1975) lysis buffer and stored at $-70^{\circ}$ for later use. The resulting labelled protein sample typically contained about $15 \mu \mathrm{g}$ of protein and had a total activity of about $1,500,000$ to $3,000,000$ counts $/ \mathrm{min}$.

Proteins of Saccharomyces cerevisiae were labelled in vivo by adding tritiated tyrosine (ICN Radiochemicals) to a minimal growth medium for yeast. 
Table 1. Mean values of morphological characters measured on a single clone of Daphnia pulex taken from each of two localities and raised in different seasonal environments (standard deviations in parentheses)

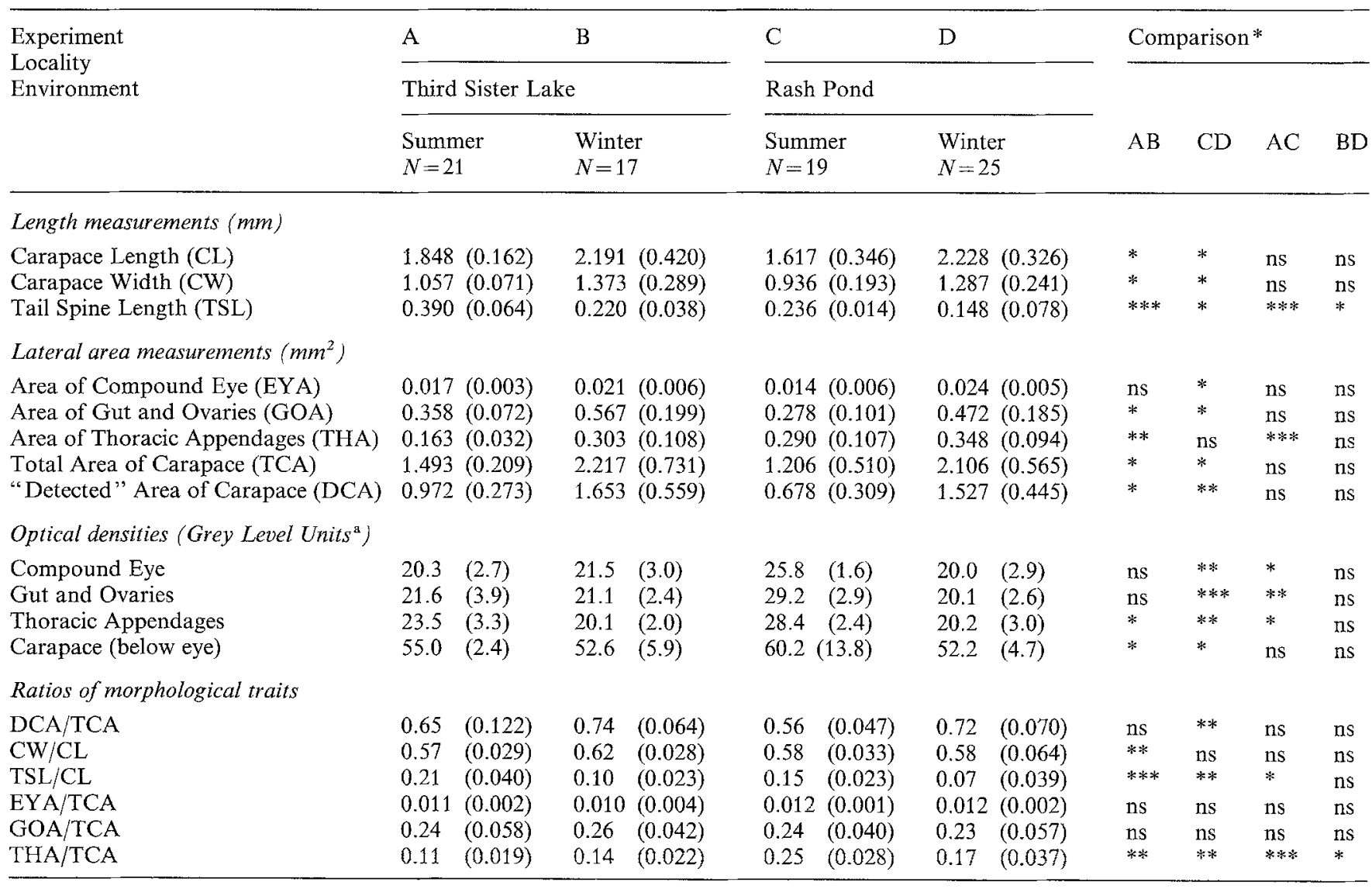

* Results of Mann-Whitney U Tests of pairwise comparisons of the morphological characters are shown for Experiments A, B, C, and D. * $P \leqq 0.025, * * P \leqq 0.005, * * * P \leqq 0.0005$, ns $=$ not significant

a Optical density is measured in terms of a "grey level" scale ranging from 0 to 64 . These values are linearly proportional to the light intensity produced by the image

Electrophoresis and autofluorography. Two-dimensional polyacrylamide gel electrophoresis (2DPAGE) was carried out according to the protocols described by O'Farrell (1975) and O'Farrell and O'Farrell (1977). The total radioactivity of each sample loaded onto the isoelectric focusing gel was approximately $1,000,000$ counts $/ \mathrm{min}$.

Autoradiographs of the dried-down SDS slab gels were made using autofluorography. The gels were exposed to Eastman Kodak X-Omat R (Code XR-5) X-ray film which had been preflashed as described by Laskey and Mills (1975). For the fluorographic enhancement, a Kodak XOmatic regular X-ray intensifying screen was used for ${ }^{125} \mathrm{I}$ labelled proteins. Satisfactory results were usually obtained with exposures of 48 to $72 \mathrm{~h}$ at $-70^{\circ}$. Autofluorography for tritium-labelled proteins was done using a sodium salicylate fluor as described by Chamberlain (1979).

In order to compare the various polypeptide patterns obtained by 2DPAGE, each autofluorograph was scored for the number and positions of major polypeptide spots. Major polypeptide spots are defined as those spots which can be unambiguously identified on the autofluorographs when they are exposed according to the procedure described above. Effects of locality and environment on the maximum number of interclonal differences were analyzed firstly by using a Chi-squared $2 \times 2$ contingency table to test for inde- pendence of these two treatments. If there was no significant interaction between the treatments, a second Chi-squared was calculated for the row and column totals separately in order to test for significant effects of each treatment separately.

\section{Results}

Morphological phenotypes. The Daphnia pulex populations from Third Sister Lake and Rash Pond both exhibit developmental plasticity of morphology in association with the seasonal environments. When single clones were raised in the laboratory under the "summer" and "winter" environments described above, phenotypic dimorphisms were observed in association with each environment. Mean values and the standard deviations of the morphological measurements and ratios of characters are shown in Table 1. The results of Mann-Whitney $U$ tests of pairwise comparisons of these mean values within localities, between seasonal environments and within seasonal environments, between localities are also shown in Table 1.

Highly significant morphological differences between individuals from the same clone occur when they are raised in different seasonal environments (Table 1). The two seasonal environments induced the expression of significant 

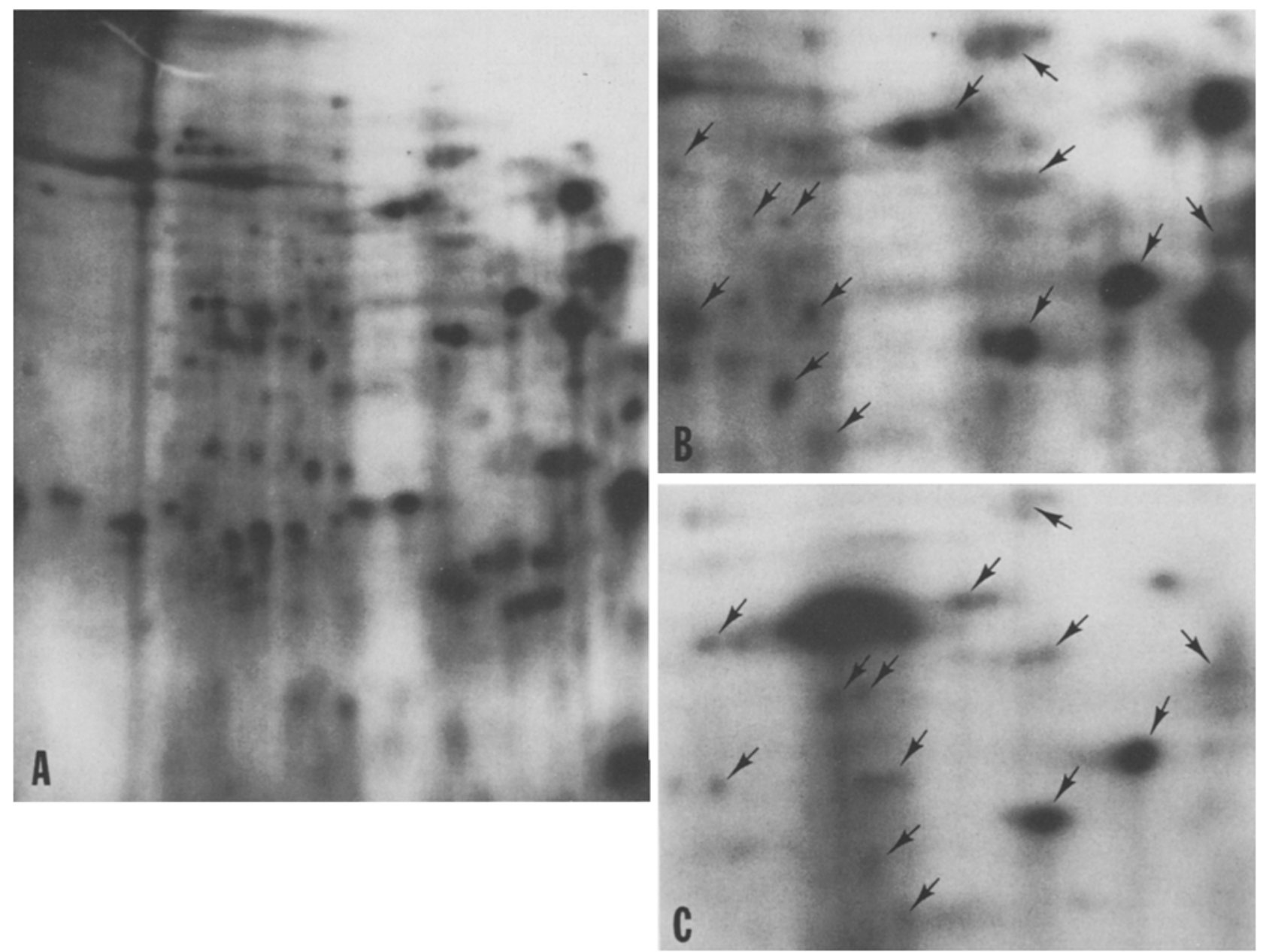

Fig. 1A-C. Autofluorographs of 2DPAGE gels of Daphnia pulex polypeptides. The autofluorographs are oriented with the high molecular weight polypeptides at the top, and low molecular weight polypeptides at the bottom. In the horizontal dimension, polypeptides with isoelectric points near $\mathrm{pH} 7$ occur at the left margin of each gel, and those with isoelectric points near $\mathrm{pH} 5$ occur at the right margin. A Autofluorograph representing polypeptides from a Rash Pond Daphnia pulex clone which has been raised in the summer laboratory environmental conditions. B Enlargement of the upper right region of Figure $1 \mathrm{~A}$. C Enlargement of the same region of an autofluorograph from the same Rash Pond clone raised under winter environmental conditions. The arrows indicate polypeptide spots which are common "landmarks" for both gels

and specific phenotypic plasticity for almost all of the characters measured and most of the ratios. This environmental effect holds for clones from both localities. Individuals raised in the summer seasonal conditions have longer tail spines, are smaller in size, and have smaller lateral areas of their most visible body parts, making them less conspicuous, overall. This is also evident from the summer forms having smaller "detected" carapace areas, both as an absolute measurement and as the ratio of detected area to actual carapace area. For the Rash Pond clone, mean optical densities for all of the characters measured are significantly lower in the summer forms than in the winter forms.

There are very few significant differences between the two localities, when individuals are raised in the same seasonal environment. This is particularly true for individuals raised in the winter environment. The tail spine length is always greater for the Third Sister Lake clone than the Rash Pond clone, regardless of whether they are both raised in the summer or the winter environment. In the summer environment, the optical densities of the compound eye, gut and ovaries, and thoracic appendages are significantly lower for the Rash Pond clone, while the area of the thoracic appendages is significantly higher in the Rash Pond clone.

Polypeptide phenotypes. Tests for the occurrence of a number of different possible artefacts during 2DPAGE caused by the iodination procedure were carried out using the yeast, Saccharomyces cerevisiae. Protein samples from a single clone of yeast cells could be adequately labelled in vivo with tritiated tyrosine in the culture medium, for comparison to the same proteins extracted from yeast cells grown with unlabelled tyrosine and subsequently labelled in vitro with ${ }^{125} \mathrm{I}$. The resulting autofluorographs of the two-dimensional gels showed that the relative positions of the polypeptide spots were identical, while only the relative intensities of a few spots differed.

For the present study a total of four different clones were analyzed from Third Sister Lake (all collected from the field in the summer), and five different clones from Rash Pond (three collected in the summer and two in the winter). For the Third Sister Lake clones, six pairs of 
Table 2. Effects of locality and season on polypeptide patterns of Daphnia pulex clones (percentages of total major polypeptide spots observed among both groups in parentheses)

Number of major polypeptide spots

\begin{tabular}{lll}
\hline Common & Unique & Total \\
to Both & to Either & Observed \\
Groups & Group & among \\
& & Both Groups
\end{tabular}

\section{Compared groups}

Summer vs. Winter

from Third Sister Lake

Summer vs. Winter

from Rash Pond

Third Sister Lake

vs. Rash Pond from

Summer Environment

Third Sister Lake

$79(49.4)$

$81(50.6)$

160

Winter Environment

Table 3. Chi-squared tests for effects of locality and season on the maximum number of interclonal differences in polypeptide spots within each locality-season combination ( $\mathrm{ns}=$ not significant)

\begin{tabular}{lll}
\hline Environment & Locality & \\
\cline { 2 - 3 } & $\begin{array}{l}\text { Third Sister Lake } \\
\text { (4 clones })\end{array}$ & $\begin{array}{l}\text { Rash Pond } \\
(5 \text { clones })\end{array}$ \\
\hline Summer & 4 & 13 \\
Winter & 9 & 18 \\
\hline
\end{tabular}

\begin{tabular}{lllll}
\hline Treatment & df & $\chi^{2}$ & $P$ \\
\hline Independence & 1 & 0.1258 & $>0.90 \mathrm{~ns}$ \\
Environment & 1 & 2.2727 & $>0.10 \mathrm{~ns}$ \\
Locality & 1 & 7.3636 & $<0.01$ \\
\hline
\end{tabular}

winter/summer environmental comparisons were made, while nine pairs were made for the Rash Pond clones. A representative autofluorograph of a two-dimensional gel is shown in Fig. $1 \mathrm{~A}$.

The results of the comparisons of the major polypeptide patterns are summarized in Tables 2 and 3 . The reproducibility was excellent among the two-dimensional gels of replicate samples taken from the same clone, raised in the same laboratory environment, with a maximum of three differences in polypeptide pattern. These variants occurred near the basic end of the $\mathrm{pH}$ gradient for the isoelectric focusing and most likely represent variability in the solubilization of these polypeptides in the lysis buffer or slight variability in the actual $\mathrm{pH}$ of the basic end of the isoelectric focusing gels.

Comparison of all two-dimensional gels from each locality revealed the existence of a subset of polypeptide spots which are common to all of the gels, regardless of environmental conditions (Table 2). These polypeptide spots are particularly important in making detailed comparisons between gels because they define local geometric patterns in

the gels which serve as reference points for the variable polypeptide spots. These polypeptide patterns are easily recognizable, even when there are small irregularities in the $\mathrm{pH}$ gradient or pore size of the slab gel which may change the absolute position (i.e. in $\mathrm{x}, \mathrm{y}$ coordinates) of a polypeptide spot in the final gel (Bloch et al. 1980).

Figures $1 \mathrm{~B}$ and $1 \mathrm{C}$ show enlargements of the same regions of pairs of autofluorographs for members of the same Rash Pond clone, raised in different seasonal environments to demonstrate the appearance of this phenotypic plasticity on the gels.

The first two rows of Table 2 examine the set of polypeptide spots expressed by all the clones from each locality, pooling together the polypeptides observed in both seasonal environments. For both localities, about $30 \%$ of all the polypeptides are invariable, and about $65 \%$ to $71 \%$ are phenotypically plastic according to the seasonal environment. The last two rows of Table 2 examine the effect of seasonal environment on the pooled polypeptides observed in both localities. About $50 \%$ of all the polypeptides observed among all winter-raised individuals are invariable, compared to about $20 \%$ for the all the summer-raised individuals.

Interclonal comparisons were made within seasonal environments for each locality (Table 3 ). This type of interclonal variation is small, but interclonal differences in expressed polypeptide spots are significantly higher among the Rash Pond clones than among the Third Sister Lake clones.

\section{Discussion}

Cyclomorphosis is an example of seasonally expressed developmental polymorphism which is controlled by environmental cues of seasonal transition. For a given individual, the polymorphic traits are permanent, morphological ones, rather than transitory physiological states. Other examples include the alary and reproductive polymorphisms observed in many species of aphids, which are controlled by such factors as photoperiod, population density, food quality, and temperature (Lees 1966; Hille Ris Lambers 1966; Mittler and Sutherland 1969); and the seasonal color polymorphisms in many species of Lepidoptera controlled by temperature and photoperiod (Shapiro 1976).

This type of adaptive phenotypic plasticity has been termed "autoregulatory morphogenesis" by Schmalhausen (1949), "adaptive polyphenism" by Mayr (1963), and "developmental conversion" by Smith-Gill (1983). These terms refer to the specific, environmentally-induced "switching" between alternate developmental programs of gene expression which results in expression of specific, alternate phenotypes. Each phenotype is correspondingly adaptive to its inducing environment. The evolution of such adaptations is most common where 1) environmental change is predictable; 2) changing proximal environmental cues (such as photoperiod) exist which are good predictors of the ultimate environmental changes (such as seasonal changes in predation); and 3) these ultimate environmental changes determine fitness values of particular phenotypic traits (such as adult carapace size). Conversely, as the predictability of the ultimate environmental changes decreases, the specificity of the phenotypically plastic response should also decrease, as there will be an advantage to producing phenotypically variable offspring. 
The present study demonstrates the very high degree of season specific phenotypic plasticity in both morphology and polypeptide phenotype which is expressed by single, isogenic clones of Daphnia pulex. Summer conditions induce morphological characters (reductions in size, shape relationships, and optical density of the non-transparent body parts) which contribute to reduced visibility. These conditions (higher temperatures and longer photoperiod) are environmental cues which are highly correlated with high abundances of visually hunting predatory associated with the "summer" environments of both localities. These same cues also signal high predation pressures from blind, invertebrate predators such as cyclopoid copepods, hence, the phenotypic response of increased tail spine length as a defense against this type of predation (Kerfoot 1975, 1977a, 1977b).

There is also a very large amount of environmentally induced phenotypic variability apparent at the level of expressed polypeptides. A very high percentage of the expressed polypeptides (Table 2) are specifically correlated with only one or the other seasonal environment, and therefore, one set of the seasonally plastic morphological characters. Moreover, similarities can be seen in the relative magnitudes of phenotypic plasticity at both the level of morphological differences and of expressed polypeptides (Tables 1 and 2). For example, the most morphologically similar groups are the clones from the two localities raised in the winter environment. These two groups also have the highest percentage of expressed polypeptides in common.

How are these differences in polypeptide phenotypes to be interpreted? 2DPAGE is an extremely sensitive technique for resolving complex mixtures of polypeptides into characteristic "maps" or "fingerprints". However, this electrophoretic technique differs from those commonly used in allozyme studies of genetic polymorphism in natural populations. A very large number of polypeptides produced at different loci are separated by their molecular weights in the second (SDS) dimension. The polypeptides of different alleles at the same loci are separated by their isoelectric points in the first dimension and appear at the same molecular weight position of the second dimension.

2DPAGE has been used to estimate the amount of genetic polymorphism in natural populations of a number of different species (Aquadro and Avise 1981; Leigh Brown and Langley 1979; Racine and Langley 1980; Smith et al. 1980). These studies generally estimate average heterozygosity per locus as being about $2 \%$, which is much lower than expectations (about 10\% to $15 \%$ ) based on similar studies using one-dimensional techniques, such as starch gel electrophoresis. These authors argue that these lower estimates of genetic variability result from the ability of 2DPAGE to survey a more unbiased sample of genetic loci than those commonly used in one-dimensional electrophoretic studies. However, it has also been shown that batteries of different one-dimensional techniques can detect more allelic variants of polypeptides than 2DPAGE alone because the latter necessitates the denaturation of the proteins (McLellan et al. 1983).

In the present study, the phenotypic plasticity observed in polypeptide expression is of two types: changes in presence or absence of polypeptide spots at the same molecular weight, and the appearance or disappearance of spots at different molecular weights (compare Figs. $1 \mathrm{~B}$ and 1C). The first type could represent changes in the expression of allozymes (i.e. alleles) of the same locus, or the switching on or off of isozymes with the same enzyme function, but expressed by other loci. An example of the latter occurs in the seasonally controlled variation in transferrin and leucine aminopeptidase electromorphs in Microtus ochrogaster described by McGovern and Tracy (1981). In the present study, however, changes in polypeptide expression within the same molecular weight cannot differentiate between switching of allozymes and isozymes because the enzyme function of the polypeptide spots is unknown.

Polypeptide spots which appear or disappear without opposite changes at the same molecular weight could represent structural genes being turned on or off, or the polypeptide products of regulatory genes which are themselves turning on or off other structural genes. 2DPAGE would also be able to resolve proteins which have been posttranslationally modified (Uterman et al. 1982), representing another class of gene regulatory mechanisms. Thus, a very wide range of different types of changes in gene expression can be detected with 2DPAGE.

The very large amounts of intraclonal, environmentally controlled variation in polypeptide expression observed here most likely represents switching between very different developmental pathways, activating different subsets of genetic loci, rather than different alleles at a similar subset of loci. This is supported by the common occurence of polypeptide spot changes across different molecular weights. However, there is no necessary relationship between the amount of expressible phenotypic plasticity and the amount of genetic polymorphism of structural genes per individual (as opposed to polymorphism within the population). It is at least theoretically possible for an individual to be $100 \%$ homozygous and still be able to express large amounts of phenotypic plasticity.

These results are consistent with the prediction that these Daphnia pulex populations consist of clones which are capable of expressing a wide range of adaptive phenotypic plasticity in response to predictable environmental change. The large amount of variability in polypeptide pattern of clones raised in different seasonal environments, and the specificity of these patterns to specific seasonal cues support the hypothesis that very different, highly canalized, alternative developmental pathways have evolved in these Daphnia pulex populations, which are specifically switched on or off by those cues.

The nature of the seasonal fluctuations in predator type and adundance is quite different in the two localities. The Daphnia pulex population in Third Sister Lake occurs only from late June to September and is concentrated within a horizontal layer near the depth of the thermocline. During the rest of the year they are not seen in the water column and probably exist exclusively as diapausing "resting" eggs. This population is very predictably subject to intense predation during the summer by planktivorous fish and copepods. Studies beginning in the 1940's (Brown and Ball 1942 a, 1942 b) at Third Sister Lake have noted the great abundance of resident planktivorous fish in Third Sister Lake. Their importance as predators on Daphnia pulex was confirmed by finding that $D$. pulex made up the bulk of the gut contents of bluegill sunfish (Lepomis macrochirus) collected during one of the summers of the present study (J Korstad, pers. comm.).

The Third Sister Lake Daphnia pulex population displays a morphological polymorphism in the field which is 
dependent on space. Individuals living just below the thermocline are very large, and have short tail spines, conspicuous internal organs, and very high hemoglobin concentrations in their hemolymph. Their location probably makes them less susceptible to visually hunting fish which rarely feed below the thermocline. Above the thermocline, where visual predators are abundant, individuals are much less conspicuous because they are smaller, have smaller internal organs, and colorless hemolymph. They also have longer tail spines. Thus, the "seasonality" of predation is spatially organized in Third Sister Lake. The "summer" conditions are found above the thermocline, where temperatures are higher and effective photoperiods longer; as compared to the "winter" conditions below the thermocline, where the temperature is $4^{\circ}$, and photoperiods effectively shorter at greater depth. Therefore, predation is extremely predictable from "seasonal" cues as long as the lake is thermally stratified.

The Daphnia pulex population in Rash Pond is subjected mainly to invertebrate predation by the larvae of both Chaoborus and odonates. During the summer, predation pressure on large individuals occurs because of the presence of the odonate larvae, which, unlike most dipteran larvae, selectively feed on the largest individuals. This source of predation is relatively less predictable because their population density varied considerably from year to year during the study. Selective predation on smaller individuals during the summer is also high because of a large, resident population of Chaoborus. During the winter the odonate larvae are absent and the Chaoborus are in a non-feeding, larval diapause stage, leaving a cyclopoid copepod as the main predator.

There is also another possible source of significant environmental unpredictability. About $10 \mathrm{~m}$ from Rash Pond is Dix Pond, which is about five times larger, and separated from Rash Pond by a flat area of dry land about $0.5 \mathrm{~m}$ higher than the surface of Dix Pond. There is a permanent population of bass in Dix Pond and in 1978 about ten young bass were observed in Rash Pond. Because young bass are planktivores, they would be significant visual predators on Daphnia pulex. It is not known how these particular bass reached Rash Pond, but it seems likely that during years with unusually heavy rains there may be sufficient temporary flooding to allow bass to migrate into Rash Pond from Dix Pond. Although these bass do not seem to be able to establish a permanent breeding population in Rash Pond, their infrequent migrations may be a very significant source of unpredictable variation in predation.

Assuming that differences in polypeptide patterns for different clones raised in the same environment represent either structural or regulatory polymorphism, the amount of interclonal variation in polypeptide pattern is greater in Rash Pond than in Third Sister Lake (Table 3). However, it should be pointed out that the amount of interclonal variation in polypeptide pattern within a population cannot be taken as a measure of the average amount of heterozygosity per locus. It is not known for Daphnia pulex whether the actual genetic differences between clones are structural or regulatory, the latter being capable of inducing many individual changes in polypeptide expression at other loci.

The amount of interclonal variation correlates well with the amount of environmental unpredictability associated with these localities. Unpredictably fluctuating environments would be expected to maintain more genetic poly- morphism in their resident populations, as particular phenotypic responses to the same seasonal cues may not always have the same relative fitness value from year to year. The very predictable spatial occurrence of predators in Third Sister Lake every year may select for a much more stereotyped (or canalized) developmental, phenotypic response. This is consistent with the smaller amounts of both intraclonal and interclonal variation in polypeptide phenotype for Third Sister Lake individuals raised in the same environment, as compared to Rash Pond individuals raised in the same environment.

Acknowledgements. I thank Julian Adams and Trevor Price for many helpful comments and suggestions which substantially improved the manuscript, and John Chamberlain for his years of advice and encouragement in the development and execution of the laboratory work. This work was done in partial fulfillment of the requirements for the Ph.D. degree at the University of Michigan and was supported by NSF grant DEB 79-23437, the NIH Predoctoral Genetics Training Program, a Rackham Predoctoral Fellowship, a Rackham Dissertation Grant, and the Walker and Hinsdale Scholarships from the Museum of Zoology.

\section{References}

Aquadro CF, Avise JC (1981) Genetic divergence between rodent species assessed by using two-dimensional electrophoresis. Proc Natl Acad Sci, USA 78:3784-3788

Bloch PL, Phillips TA, Neidhardt FC (1980) Protein identifications on O'Farrell two-dimensional gels: locations of 81 Escherichia coli proteins. J Bacteriol 141:1409-1420

Brooks JL (1968) The effects of prey size selection by lake planktivores. Syst Zool 17:272-291

Brown CJD, Ball RC (1942a) A fish population study of Third Sister Lake. Trans Amer Fish Soc 72:177-186

Brown CJD, Ball RC (1942b) An experiment in the use of Derris Root (rotenone) on the fish and fish-food organisms of Third Sister Lake. Trans Amer Fish Soc 72:267-284

Chamberlain JP (1979) Fluorographic detection of radioactivity in polyacrylamide gels with a water-soluble fluor, sodium salicylate. Analyt Biochem 98:132-135

Dodson SI (1974) Adaptive changes in plankton morphology in response to size-selective predation: a new hypothesis of cyclomorphosis. Limnol Oceanog 19:721-729

Fedorenko AY (1975) Feeding characteristics and predation impact of Chaoborus (Diptera, Chaoboridae) larvae in a small lake. Limnol Oceanog 20:250-258

Feller W (1968) An introduction to probability theory and its applications, vol 1, third edition. John Wiley and Sons, New York

Fraker PJ, Speck JC (1978) Protein and cell iodinations with a sparingly soluble chloramide 1,3,4,6-tetrachloro-3 $3 \alpha, 6 \alpha$-diphenylglycoluril. Biochem Biophys Res Comm 80:849-857

Galbraith MG Jr (1967) Size-selective predation on Daphnia by rainbow trout and yellow perch. Trans Amer Fish Soc 96:1-10

Hebert PDN, Ward RD (1972) Inheritance during parthenogenesis in Daphnia magna. Genetics $71: 639-642$

Hille Ris Lambers D (1966) Polymorphism in Aphididae. Ann Rev Entomol 11:47-78

Hutchinson GE (1967) A treatise on limnology, vol 2. John Wiley and Sons, New York

Jacobs J (1966) Predation and rate of evolution in cyclomorphic Daphnia. Verh Int Ver Limnol 16:1645-1652

Kerfoot WC (1975) The divergence of adjacent populations. Ecology $56: 1298-1313$

Kerfoot WC (1977a) Implications of copepod predation. Limnol Oceanog 22:316-325

Kerfoot WC (1977b) Competition in cladoceran communities: the cost of evolving defenses against copepod predation. Ecology $58: 303-313$ 
Kerfoot WC (1978) Combat between predatory copepods and their prey: Cyclops, Epischura, and Bosmina. Limnol Oceanog 23:1089-1102

Kerfoot WC (1980) Perspectives on cyclomotphosis: separation of phenotypes and genotypes. In: Kerfoot WC (ed) Evolution and ecology of zooplankton communities. University Press of New England, Hanover, New Hampshire, pp 470 496

Laskey RA, Mills AD (1975) Quantitative film detection of $\mathrm{H}-3$ and $\mathrm{C}-14$ in polyacrylamide gels by fluorography. Eur J Biochem 56:335-341

Lauterborn R (1904) II. Teil. Die cyklische oder temporale Variation von Anuraea cochlearis. Verh naturh-med Ver Heidelb $7: 529-621$

Lees AD (1966) The control of polymorphism in aphids. Adv Insect Physiol 3:207-277

Leigh Brown AJ, Langley CH (1979) Reevaluation of level of genic heterozygosity in natural populations of Drosophila melanogaster by two-dimensional electrophoresis. Proc Natl Acad Sci, USA 76:2381-2384

Mayr E (1963) Animal species and evolution. Belknap Press, Cambridge, Mass

McGhee JD, von Hippel PH (1977) Formaldehyde as a probe of DNA structure. 4. Mechanisms of initial reaction of formaldehyde with DNA. Biochem 16:3267-3276

McGovern M, Tracy CR (1981) Phenotypic variation in electromorphs previously considered to be genetic markers in Microtus ochrogaster. Oecologia (Berlin) 51:276-280

McLellan T, Ames GF-L, Nikaido K (1983) Genetic variation in proteins: comparison of one-dimensional and two-dimensional gel electrophoresis. Genetics 104:381-390

Mittler TE, Sutherland ORW (1969) Dietary influences on aphid polymorphisms. Entomol Exp et Appl 12:703-713

Mosimann JE, James FC (1979) New statistical methods for allometry with application to Florida red-winged blackbirds. Evolution 33:444-459

O'Brien WJ, Vinyard GL (1978) Polymorphism and predation: the effect of invertebrate predation on the distribution of two varieties of Daphnia carinata in South India ponds. Limnol Oceanog 23:452 460

O'Brien WJ, Kettle D, Riessen H (1979) Helmets and invisible armor: Structures reducing predation from tactile and visual planktivores. Ecology 60:287-294

O'Farrell PH (1975) High resolution two-dimensional electrophoresis of proteins. J Biol Chem 250:4007-4021

O'Farrell PH, O'Farrell PZ (1977) Two-dimensional polyacrylamide gel electrophoretic fractionation. In: Stein G, Stein $J$, Kleinsmith LJ (ed) Methods in cell biology, vol 16. Chromatin and chromosomal protein research. I. Academic Press, New York, pp 407-420

Racine RR, Langley CH (1980) Genetic heterogygosity in a natural population of Mus musculus assessed using two-dimensional electrophoresis. Nature 283:855-857

Schmalhausen II (1949) Factors of evolution : the theory of stabilizing selection. Blakiston, Philadelphia.

Shapiro AM (1976) Seasonal polyphenism. Evol Biol 9:259-333

Smith SC, Racine RR, Langley CH (1980) Lack of genic variation in the abundant proteins of the human kidney. Genetics 96:967-974

Smith-Gill SJ (1983) Developmental plasticity: developmental conversion versus phenotypic modulation. Amer Zool 23:47-55

Uterman G, Steinmetz A, Weber W (1982) Genetic control of human apolipoprotein $E$ polymorphism: comparison of one- and two-dimensional techniques of isoprotein analysis. Hum Genet $60: 344-351$

Zaffagnini F, Sabelli B (1972) Karyological observations on the maturation of the summer and winter eggs of Daphnia pulex and Daphnia middendorffiana. Chromosoma 36:193-203

Zaret TM (1972) Predator-prey interaction in a tropical lacustrine ecosystem. Ecology 53:248-257

Received November 3, 1983 